\title{
Wildlife conservation and animal temperament: causes and consequences of evolutionary change for captive, reintroduced, and wild populations
}

\author{
P. T. McDougall ${ }^{1}$, D. Réale ${ }^{2}$, D. Sol ${ }^{1,3}$ \& S. M. Reader ${ }^{1,4}$ \\ 1 Department of Biology, McGill University, Montréal, Québec, Canada \\ 2 Canadian Research Chair in Behavioural Ecology and Groupe de Recherche en Écologie Comportementale et Animale, Département des \\ sciences Biologiques, Université du Québec à Montréal, Succursale Centre-ville, Montréal, Québec, Canada \\ 3 Centre de Recerca Ecològica i Aplicacions Forestals (CREAF), Campus de la Universitat Autònoma de Barcelona, Bellaterra, Catalonia, Spain \\ 4 Behavioural Biology, Department of Biology, University of Utrecht, Utrecht, The Netherlands
}

\begin{abstract}
Keywords
animal temperament; personality; contemporary evolution; captivity; shy-bold; reintroductions.

\section{Correspondence \\ P.T. McDougall. Current address: Department of Zoology, Oregon State University, 3029 Cordley Hall, Corvallis, Oregon 97331, USA. \\ Email: mcdougallpeter@gmail.com}

Received 27 October 2004; accepted 27 June 2005

doi:10.1111/j.1469-1795.2005.00004.x

\begin{abstract}
We argue that animal temperament is an important concept for wildlife conservation science and review causes and consequences of evolutionary changes in temperament traits that may occur in captive-breeding programmes. An evolutionary perspective is valid because temperament traits are heritable, linked to fitness and potentially subject to intense selection in captivity. Natural, sexual and artificial selection can cause permanent shifts in temperament, reducing the diversity of temperament traits, diversity that may be critical to reintroduction success. Breeding programmes that ignore temperament risk leading the captive population towards domestication. Furthermore, shifts in temperament may involve alterations in linked morphological and physiological traits, and selection may even change functional relationships between traits. Captive-breeding programmes can reduce changes in temperaments by closely monitoring temperament traits, equalizing reproductive success between temperament morphs and using environmental enrichment to reduce captive stress. Under certain circumstances, knowledge about temperament may also provide a useful tool to optimize captive reproduction and to increase reintroduction success. Outside reintroduction programmes, temperament can mediate responses to human contact, hunting, exploitation, habitat fragmentation and disease transmission. Consideration of temperaments could strengthen both captive and wild conservation efforts.
\end{abstract}

\section{Introduction}

Behavioural studies are a fundamental addition to animal conservation (Curio, 1996; Clemmons \& Buccholz, 1997; Sutherland, 1998; Gosling \& Sutherland, 2000; Griffin, Blumstein \& Evans, 2000; Festa-Bianchet \& Apollonio, 2003). In general, behavioural research tends to focus on the central tendency of behaviour traits, and less on the individual variation for those traits. Nevertheless, increasing evidence from several fields indicates that individuals - and even populations - differ in their behaviour in a consistent manner (animal science: Boissy, 1995; Grandin, 1998; psychology: Gosling, 2001; behavioural sciences: Clark \& Ehlinger, 1987; Koolhaas et al., 1999; evolutionary ecology: Stamps, 1991; Wilson et al., 1994; Sih, Bell \& Johnson, 2004). These behavioural differences arise from variation in temperament traits and may significantly affect the way individuals interact with the environment, thereby influencing Darwinian fitness (e.g. Armitage, 1986; Carlstead,
Mellen \& Kleiman, 1999b; Wielebnowski, 1999; Réale et al., 2000; Dingemanse et al., 2004). Building on previous ideas (e.g. Arcese, 2003; Steel \& Hogg, 2003), we suggest that consideration of temperament differences offers a new and beneficial perspective for wildlife conservation programmes.

'Temperament' refers to relatively consistent individual dispositions that underlie and modulate the expression of behaviour. These dispositions result from the combined influences of genetic, epigenetic (i.e. developmental) and environmental effects (Buss et al., 1987). The concept of temperament implies a consistency in the character over time and across different behavioural contexts and ecological situations (Clark \& Ehlinger, 1987; Wilson et al., 1994; Gosling, 2001; Sih et al., 2004). For instance, certain streamside salamander Ambystoma barbouri individuals consistently exhibit high activity levels, emerging frequently from, and moving actively while outside of refuges (Sih, Kats \& Maurer, 2000). This temperament trait is consistent under 
different behavioural contexts (e.g. antipredator and foraging behaviour) and under different ecological situations (e.g. presence and absence of fish predators; Sih et al., 2000). In the psychological literature, individual temperament is often described by a series of temperament axes or traits that typically include activity, tameness, aggressiveness, exploration, sociability and boldness (Gosling, 2001). Differences in temperament can lead to individual differences in behaviour patterns relevant to conservation, such as anti-predator, foraging and exploratory behaviour (Godin \& Davis, 1995; Coss \& Biardi, 1997; Coleman \& Wilson, 1998; Fraser et al., 2001; Dingemanse et al., 2003; Drent, van Oers \& van Noordwijk, 2003). These dispositions are measurable through direct observation and testing in the field and laboratory (Table 1).

Wild and captive animal populations may show surprisingly rapid changes in temperament as a consequence of learning, development and evolution (Marliave, Gergits \& Aota, 1993; Trut, 1999; Drent et al., 2003). Humans may deliberately attempt to modify animal temperaments, but human-induced changes are often an unexpected, unplanned and detrimental side effect of human activities like captive breeding and hand-feeding wild animals. These changes can affect the success of conservation strategies, and embracing the individual approach by conserving the full range of temperaments is likely to play an important role in animal conservation.

To illustrate this role of temperament in conservation, we review the evolutionary alteration of temperament traits in captive-breeding programmes and its potential impact on the success of conservation strategies. We also present suggestions for reducing this impact, and for using temperament traits as tools to improve conservation practices. We conclude by highlighting areas where temperament studies may have applications to conservation in the wild.

\section{Causes of 'contemporary' evolutionary change in temperament}

Evolutionary change results when selective forces act on heritable traits that are related to individual fitness (Falconer \& Mackay, 1996). 'Contemporary evolution' refers to evolutionary change that takes place over less than a few hundred years (Hendry \& Kinnison, 1999; Stockwell, Hendry \& Kinnison, 2003), possibly within the time scale of a human lifetime (Ashley et al., 2003). Strong selective pressures on heritable traits can result in rapid evolution during captive-breeding and reintroduction programmes

Table 1 A non-exhaustive list of temperament traits and some tests used to measure them

\begin{tabular}{|c|c|c|}
\hline Traits $^{a}$ & Tests & Reference \\
\hline Neophobia and exploration & $\begin{array}{l}\text { Latency to approach a novel object } \\
\text { Behaviour in a novel environment } \\
\text { (e.g. open field test; holeboard test) } \\
\text { Latency to eat novel food }\end{array}$ & $\begin{array}{l}\text { Archer (1973), Walsh \& Cummins (1976), } \\
\text { Greenberg \& Mettke-Hoffman (2001) }\end{array}$ \\
\hline Boldness $^{\mathrm{b}}$ & $\begin{array}{l}\text { Trappability } \\
\text { Response to threat stimuli } \\
\text { (e.g. predator stimuli; umbrella test) }\end{array}$ & Boissy (1995), Gosling (2001) \\
\hline Tameness & $\begin{array}{l}\text { Resistance to handlers } \\
\text { Tonic immobility } \\
\text { Direct observation }{ }^{c}\end{array}$ & Grandin (1998), Price (2002) \\
\hline Activity & $\begin{array}{l}\text { Open field test } \\
\text { Direct observation }^{c}\end{array}$ & Archer (1973) \\
\hline Aggressiveness & $\begin{array}{l}\text { Latency to attack a mirror image stimulus (mirror test) } \\
\text { Latency to attack a model of conspecific } \\
\text { Latency to attack a standard conspecific opponent } \\
\text { Direct observation }{ }^{c}\end{array}$ & Earley, Hsu \& Wolf (2000), De Boer et al. (2003) \\
\hline Sociability & $\begin{array}{l}\text { Latency to approach conspecific } \\
\text { Direct observation }^{c}\end{array}$ & Faure \& Mills (1998) \\
\hline
\end{tabular}

It can be assumed that each trait represents a continuum with individuals showing a different degree of response. For instance, boldness can be considered as a continuum with shy and bold individuals at the extremes of the range (Wilson et al., 1994).

aSome authors use the term 'coping style' (Koolhaas et al., 1999) to refer to a set of correlated temperament or personality traits; individuals are classified into a proactive/reactive gradient depending on how they cope with a stressful or challenging situation. Coping styles and temperament traits can be linked together. For instance, proactive individuals can be considered as non-neophobic and exploratory, bold, tame, aggressive, generally active, non-flexible individuals, whereas neophobic and unexploratory, shy, non-aggressive, less active, and highly flexible individuals can be considered as reactive.

b'Fearfulness' can be used as an equivalent to shyness, the opposite of boldness (see Boissy, 1995).

'Direct observation can be used to measure temperament traits, with the exception of neophobia and boldness, which need to be measured under experimental conditions. Observation can be conducted according to the general ethological approach, which consists of collecting frequencies and/or durations of behaviour events or patterns, using an ethogram (see Carlstead, 1999), or by observer's ratings (for reviews see: Manteca \& Deag, 1993; Carlstead, 1999; Gosling, 2001). 
(Stockwell et al., 2003), as well as in wild populations (Endler, 1986; Hendry \& Kinnison, 1999). Conservationists have tended to neglect contemporary evolution, perhaps because of the persistence of the traditional view that evolutionary processes act solely on geological time scales. Its central importance in conservation strategies, however, has recently gained recognition (Conover \& Munch, 2002; Ashley et al., 2003; Stockwell et al., 2003).

In order for a trait to evolve in response to environmental changes, genetic variance must underlie the phenotypic variance of that trait (Lynch \& Walsh, 1998). Pedigree analyses and artificial selection experiments have confirmed the genetic basis of temperament traits in both wild and domestic species (Gerken \& Petersen, 1992; Trut, 1999; Hansen \& Møller, 2001; Dingemanse et al., 2002; Malmkvist \& Hansen, 2002; Drent et al., 2003). A second condition for contemporary evolution to affect changes in temperament is a link to individual fitness. Association between temperament traits and fitness traits (e.g. reproductive success or survival) has been shown both in captivity (e.g. fearfulness in cheetahs Acinonyx jubatus, Wielebnowski, 1999; aggressiveness in black rhinoceroses Diceros bicornis, Carlstead et al., 1999b) and in the wild (e.g. sociality in yellow-bellied marmots Marmota flaviventris, Armitage, 1986; docility and boldness in bighorn ewes Ovis canadensis, Réale et al., 2000; boldness and exploratory behaviour in great tits Parus major, Dingemanse et al., 2004). Furthermore, the existence of sets of correlated temperament traits, or of some links between temperament and morphological or physiological traits, is common to many species (Koolhaas et al., 1999; Trut, 1999; Sih et al., 2004), suggesting an even more complex relationship between temperament and individual fitness.

\section{Evolutionary changes in captivity and consequences for reintroductions}

\section{Alteration of temperament traits in captive conditions}

A potential drawback of captive breeding is a change in the evolutionary trajectory of wild animals. This shift can result both from the novel conditions seen in captivity and from husbandry practices that would favour particular geno/phenotypes (Arnold, 1995; Carlstead, 1996; Gilligan \& Frankham, 2003). Due to new selective pressures, the genetic and phenotypic characteristics of captive stocks can diverge from those of their population of origin. Since individuals respond differently to the stress of captivity (Arnold, 1995; Carlstead, 1996; Crockett, Shimoji \& Bowden, 2000), temperament traits may play a key role in determining the effects of selection.

Natural, sexual and artificial (anthropogenic) selection can all affect captive populations. Natural selection can exert novel pressures on a population placed in the new captive environment. Furthermore, the relaxation of natural selection can result in the persistence of behavioural traits and deleterious genes that are selected against in the wild (Carlstead, 1996; Woodworth et al., 2002). In general, highly active or very aggressive animals are more likely to be poorly adapted to captive conditions than less active and less aggressive animals. Selective pressures would therefore disfavour aggressiveness and activity compared to other traits. The lower aggressiveness and higher docility of many laboratory rodent strains compared to wild strains support this idea (De Boer, van der Vegt \& Koolhaas, 2003; Künzl et al., 2003). Additionally, traits related to temperament can be modified by selection in captivity; in primates, infant mortality can result from the inadequate, temperamentrelated behaviour of their mothers (Maestripieri, 1993; Fairbanks, 1996; Cleveland et al., 2004).

Sexual selection can also alter temperament traits. For example, in mink Mustela vison, 'confident/curious' individuals tended to mate earlier than the rest of the population (Malmkvist, Houbak \& Hansen, 1997). In guppies Poecilia reticulata, females showed a preference to mate with bolder males than with shy males (Godin \& Dugatkin, 1996). Note, however, that these selective pressures, with the possible exception of the relaxation of natural selection, are carefully monitored in conservation-oriented captive-breeding programmes. The use of studbooks, artificial insemination and carefully structured breeding programmes are all important means of equalizing the reproductive output of each individual present in a captive population (Loebel et al., 1992; Allendorf, 1993; Frankham et al., 2000).

Artificial (anthropogenic) selection, on the other hand, is perhaps the most important process of evolutionary change in captive populations. Darwin (1882, cited in Arnold, 1995) distinguished between methodical and unconscious forms of artificial selection. Since the late 1960s, research by Belyaev has demonstrated that selective breeding in foxes Vulpes vulpes produced major shifts in morphology, physiology and temperament (Belyaev, 1979; Trut, 1999). Since then, a number of studies have documented this rapid evolution in a number of captive populations as a result of artificial selection (fox, Korhonen \& Niemela, 1995; mink, Hansen, 1996; mouse Mus musculus, DeFries, Gervais \& Thomas, 1978; great tit, Drent et al., 2003; van Oers, Drent \& van Noordwijk, 2004; poultry, Faure \& Mills, 1998). This form of directed and methodical selection should only occur in non-conservation initiatives; studies have proposed this approach to facilitate the management of permanently captive populations in zoos (Aengus \& Millam, 1999; van Heezik \& Seddon, 2001). Unconscious selection, however, poses a large risk to conservation-oriented captive-breeding programmes.

Unconscious selection may be pervasive. It can occur through the actions of zookeepers, through rearing conditions in the facilities and through handling and husbandry procedures. As zookeepers possess the capacity to accurately and consistently rate the temperaments of the animals in their care (Carlstead, 1999), the opportunity to unconsciously favour certain temperaments when caring for or monitoring individuals exists. Furthermore, rearing conditions and enclosure characteristics can strongly influence the 
stress levels and well-being of certain individuals (e.g. enclosure area for rhinoceroses, Carlstead et al., 1999a; presence of a platform for foxes, Korhonen \& Niemela, 1995). Husbandry techniques and handling procedures may also inadvertently lead to selection by increasing stress levels in the less tame. In a study on captive coonstripe shrimp Pandalus danae, individuals that struggled to escape from handling procedures incurred significant fitness costs (Marliave et al., 1993). The population experienced an unconscious selection for tamer individuals, consequently evolving a decreased escape response within 10 generations.

\section{Consequences for reintroduction programmes}

Evolutionary shifts in captivity are a major concern for reintroduction programmes (Frankham et al., 1986; Kleiman, 1989; Woodworth et al., 2002). Few would argue against the necessity of reintroduced animals possessing adequate foraging, anti-predator and social behavioural strategies, yet studies rarely mention the importance of an adequate complement of temperament traits (Box, 1991). This is surprising, given that temperament is linked to antipredator, foraging and exploratory behaviours, but less surprising given that many of these links remain unexplored in reintroduction settings.

In a study evaluating species translocations and reintroductions, programmes using captive-reared animals had half the success of programmes that used wild-caught animals ( $75 \%$ vs. $38 \%$ success for wild-caught vs. captive reared, Griffith et al., 1989; see also Wolf et al., 1998). Temperament deficiencies could be partly responsible for this difference. In oldfield mice Peromyscus poloniotus, for example, individuals maintained in captivity for several generations no longer demonstrated appropriate anti-predator reactions (McPhee, 2004). Captive mice were less cautious, spent more time in an open area and were less likely to stay in a shelter after being exposed to a predator, suggesting that differences in anti-predator behaviour could be related to selection for bolder individuals in captivity.

Selection on temperament in captivity may also alter a suite of life history, morphological and physiological traits appropriate to life in the wild. For species in the wild, these suites are likely to be functionally related and shaped by the long-term action of natural selection (Clark \& Ehlinger, 1987; Sih et al., 2004). Selective pressures in captivity and the effects of associated inbreeding can break the functional links between traits, resulting in non-adaptive trait combinations. When the coonstripe shrimp were inadvertently selected for tameness, subsequent generations were characterized by a loss of pigment and an increased growth rate (Marliave et al., 1993). Currently, our knowledge is limited as to which temperament traits are the most important for the survival of a newly reintroduced individual. Although studies show that variation in temperament traits exists in the wild (Armitage, 1986; Réale et al., 2000; Dingemanse et al., 2004), how this variation affects the fitness of wild populations remains largely unknown. Nevertheless, it is unlikely that variation in temperament traits is present by chance alone, and so neglecting temperament may have farreaching consequences for captive populations.

\section{Loss of variation in temperament traits and the evolutionary potential of reintroduced populations}

The genetic variance of a trait may decrease in captivity as a result of the eroding action of selection (Falconer \& Mackay, 1996), a loss that may be difficult or even impossible to recuperate (Kleiman, 1989). A lack of variation reduces the capacity of the population for local adaptation in a new habitat (Falconer \& Mackay, 1996; Lynch \& Walsh, 1998), decreasing the chance of long-term persistence of the population after reintroduction (Frankham et al., 1986). Moreover, different temperament traits may be advantageous at different stages of environmental fluctuation or in different environments (Dingemanse, 2003), making maintenance of the genetic diversity underlying variance in temperament potentially crucial to reintroduction success.

The genetic variance of a trait may instead be enhanced in captivity if individuals at either extreme of a trait's distribution do not suffer from strong mortality. With the relaxation of selection in captivity, the genetic variance of a population is not held in check as it is in the wild. To date, McPhee (2004) is the only study supporting this hypothesis, with the variance in behavioural responses of oldfield mice to predators increasing with time spent in captivity. McPhee's results, however, are limited to the phenotypic variance of behavioural traits. Further work is needed to test this hypothesis at the genetic level.

\section{Avoiding evolutionary change in breeding programmes}

The first step in managing the detrimental consequences of evolutionary change in temperament consists of monitoring the traits themselves. Thus temperament traits must be measured in a repeatable and comparable manner. Detailed protocols are available for measuring the temperament of captive animals in zoos in order to improve management techniques (Carlstead, 1999; see Table 1 for additional temperament tests). Additionally, new methodologies and frameworks of relevance to ecologists are being developed for the measurement of temperament traits (D. Réale, S.M. Reader, D. Sol., P.T. McDougall \& N.J. Dingemanse, unpubl. data; Sih et al., 2004). Using this information, one may identify the links between temperament and fitness that may lead to evolutionary responses (Carlstead, 1999; Carlstead et al., 1999a,b; Wielebnowski, 1999).

Captive-breeding programmes use many techniques to ensure that every individual reproduces. Nevertheless, stress is a major barrier to captive reproductive success (van Heezik \& Seddon, 2001), and not all individuals respond to the stress of captivity in the same way (Arnold, 1995; Carlstead, 1996; Crockett et al., 2000). Stress may result 
from the short-term effects of capture and transportation (Carlstead, 1996; Korhonen et al., 2000), or the physical characteristics of the captive environment (Korhonen \& Niemela, 1995; Carlstead et al., 1999a). Even when closely managing breeding through the use of artificial insemination and studbooks, stress related to temperament differences may directly interfere with pregnancies (Zhang, Swaisgood $\&$ Zhang, 2004) or offspring survival (Korhonen, Jauhiainen \& Rekilä, 2002; Cleveland et al., 2004; Zhang et al., 2004). By identifying the temperament traits that correlate with elevated stress levels during husbandry techniques, procedures can be specifically tailored to reduce stress in particularly susceptible individuals.

Environmental enrichment is another effective method of reducing captive stress (Carlstead, 1996). The primary objectives of enrichment are to avoid undesirable behaviours associated with stress in captivity - stereotypies and high aggression - and to encourage individuals to behave naturally (Carlstead, 1996). Studies have reported significant reduction in stress after environmental enrichment (Korhonen \& Niemela, 1995), but few considered how this enrichment could interact with temperament. Despite increasing the overall reproductive success of a captive population, enrichment risks introducing increased variation by enhancing the fitness of a particular genotype or set of temperament traits (Fig. 1a). The resulting fitness advantage for a subset of the population could affect an evolutionary shift in the captive stock. Alternatively, enrichment could both increase the average reproductive success in the population, as well as reduce potential variation in fitness among individuals (Fig. 1b). Thus, it remains unclear whether the benefits in terms of breeding success for the entire captive population are optimized by selecting for breeding those individuals with more appropriate temperaments for captivity or, alternatively, by providing good breeding conditions for all individuals independent of their temperament. Nevertheless, a better understanding of possible interactions between temperament traits and enrichment programmes is (a) Enrichment increases fitness but increases variation as well

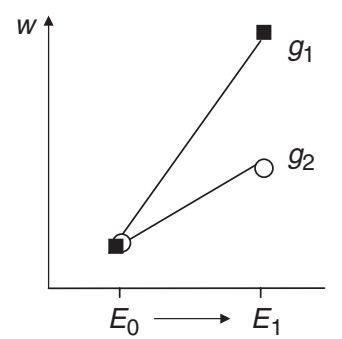

(b) Enrichment increases fitness and decreases variation

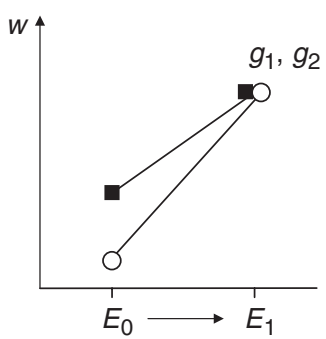

Figure 1 The two graphs demonstrate the potential drawbacks of ignoring interactions between temperament traits and environmental enrichment in captivity. $E_{0}$ and $E_{1}$ represent non-enriched and enriched environments, respectively; $g_{1}$ and $g_{2}$ represent genotypes at opposite extremes of a temperament trait; $w$ represents fitness, or lifetime reproductive success. necessary to avoid unexpected outcomes in a captive-breeding programme.

\section{Temperament as a tool for captive- breeding programmes}

This review so far emphasizes the problems and solutions associated with evolutionary changes in temperament, yet the planned alteration of temperament may also prove beneficial to conservation efforts (Stockwell et al., 2003). Maintaining genetic variability of a captive stock is sometimes less important than establishing a viable breeding population in captivity, especially with species at extreme risk of extinction (Frankham et al., 1986). In situations where it is crucial to establish successful breeding in captive stocks, methodical selection could and should concentrate on those temperament traits that favour breeding in captivity (Frankham et al., 1986). Similarly, programmes should employ enrichment methods that result in the highest reproductive success, even at the cost of introducing a greater amount of variation into the captive population (Fig. 1a).

Knowledge of temperament traits can help increase reproductive success in captive stocks, and it can help increase the reintroduction success too. Recent reintroduction and translocation programmes have proposed training captive-bred animals to cope with specific challenges in their new habitat such as avoiding predators or finding appropriate food (Curio, 1996; Griffin et al., 2000). Active screening for certain genotypes is also a current discussion topic in conservation biology (Stockwell et al., 2003), but this screening for temperaments requires a good understanding of the temperament-ecology interactions in a system. For example, activity, mobility and exploration may affect the way a newly introduced individual will familiarize itself with its new habitat - elevated mobility levels of captive-raised voles Microtus rossiaemeridionalis decreased predatorinduced mortality during the first three days after introduction (Banks, Norrdahl \& Korpimäki, 2003). Conversely, bold or exploratory individuals could experience higher risks of predation, poisoning or accident as well as possibly limiting reproductive success between released individuals (Woodroffe, 2003). It is possible that certain temperament traits are required at different stages of a reintroduction process (e.g. initial releases could favour boldness whereas second stage releases should include primarily shy individuals). Current knowledge on this topic is limited, however, and research should utilize ongoing reintroduction programmes as a source of valuable data on the influence of temperament.

\section{Future directions: temperament in the wild}

Animal temperament studies have focused primarily on the captive environment (Gosling, 2001), but human activities can also influence animal temperament in the wild. Frequent human-animal interactions occur in nature as a result of 
direct human contact or of human encroachment, and humans can cause changes in wild animal behaviour (Mattson, Blanchard \& Knight, 1992; Lord, Waas \& Innes, 1997; Anthony \& Blumstein, 2000; Louis \& Le Beere, 2000; Lacy $\&$ Martins, 2003). Both reversible phenotypic plasticity and contemporary evolution may be responsible for such behavioural changes. Individuals may respond differently to a disturbance depending on their temperament.

Below, we highlight four areas of conservation research that could benefit from considering the study of temperament. Each involves situations whereby stressing a subset of individuals, depending on their temperament, could result in evolutionary changes in a wild population. Further research into these and related areas is crucial to gain a better understanding of how temperament influences wild populations.

\section{Contact with humans}

Humans can alter the selective pressures experienced by animals in the wild, with animals that venture close to human habitations in search of food providing an obvious example. In Alaskan brown bears Ursus middendorffi, the seasonal use of foraging resources was affected by their degree of habituation to humans (Olson, Gilbert \& Squibb, 1997). Habituated bears used a stream resource much earlier in the fall feeding period than unhabituated bears as a result of nearby human fishing activity. Not all individuals were equally capable of habituating (Olson et al., 1997), so habituation is potentially subject to selection. Furthermore, the advantage provided to habituated animals in terms of access to increased food resources is potentially at odds with the risks associated with proximity to humans. For example, grizzly bears Ursus arctos horribilis that approached human habitations suffered an increased mortality rate compared to individuals that remain at a distance (Mattson et al., 1992). Even such simple and widespread actions as feeding wild animals may inadvertently alter temperament in a subset of a population, potentially to the detriment of the entire population.

\section{Hunting and exploitation}

Predation pressure can result in direct selection on prey temperaments (Réale \& Festa-Bianchet, 2003). As with life history or morphological traits (Conover \& Munch, 2002; Coltman et al., 2003), selective pressures resulting from hunting, trapping or fishing may affect several temperament traits such as sociability, activity or exploration. For example, hunting could affect the social system of a species if individuals were more sensitive to harvest according to their sociability. Long-term selective pressures by humans may have resulted in lower aggressiveness of brown bears Ursus arctos towards humans, and higher coexistence of wolves Canis lupus with humans in Europe compared to North America (Festa-Bianchet, 2003). Similarly, because hunting efforts are likely to target the boldest and most visible individuals of a population, a resulting overall shift in temperament could lead to a shyer population. Hunting or increased human contact may also have indirect effects on the temperament of a species by changing the composition and abundance of its predators (Berger, Swenson \& Persson, 2001). Such changes in temperament can have far-reaching effects on the average fitness of a wild population.

\section{Habitat fragmentation, mobility and dispersal}

Dispersal is of great importance to conservationists (Sutherland, 1998; Travis \& Dytham, 1999), particularly because of the consequences of habitat fragmentation on population genetics and demography (Sutherland, 1998; Anthony \& Blumstein, 2000). For instance, a more mobile animal requires a much larger area for conservation management (Thomas, Baguette \& Lewis, 2000). Differences in dispersal exist between individuals within a population (Trefilov et al., 2000; Fraser et al., 2001; Dingemanse et al., 2003) and between populations (Travis \& Dytham, 1999). Temperament relates to at least part of this variation in dispersal (Fraser et al., 2001; Dingemanse et al., 2003). Exploratory great tits, for example, tend to disperse further away than less exploratory ones (Dingemanse et al., 2003).

Patterns of dispersal are also determined in part by an animal's response to habitat margins. Willingness to enter unsuitable habitat differs from species to species (Woodroffe, 2003), and likely from individual to individual too. Increasing fragmentation could favour unexploratory and non-dispersive individuals, which would further reinforce the effects of fragmentation. Such problems may also occur in nature reserves. As dispersers experience a higher risk of mortality outside the reserve than would non-dispersing individuals (Woodroffe, 2003), a subset of the population is experiencing increased selective pressures.

\section{Disease transmission}

Temperament may also play a role in the transmission of parasites and diseases between populations. For instance, it is believed that in the cat Felis catus, the feline immunodeficiency virus (FIV) is primarily transmitted by biting, and is therefore more common in aggressive individuals (Fromont et al., 1997). In contrast, transmission of the feline leukemia virus (FeLV) occurs during affiliative interactions between cats (Fromont et al., 1997). Pontier et al. (1998) identified a strong link between orange coloration and increased aggression in cats, and orange cats are more often infected by FIV and less often infected by FeLV (Pontier et al., 1998). The prevalence of FeLV is also higher in urban populations, which are characterized by lower aggression levels. Thus, a specific temperament trait like aggression may be linked to disease and to disease transmission. Shifts in temperament may affect a wild population's susceptibility to disease.

\section{Conclusions}

Temperament traits are subject to selective pressures, which can result in rapid evolutionary changes in populations both 
in captivity and in the wild. As shifts in temperament can affect the mean fitness of a population, they can potentially alter the outcome of conservation programmes. Temperament likely plays a large role in the success of conservation efforts, yet it remains largely unexplored. We still have much to learn about how temperament functions in the wild. Even though a handful of studies already address these questions, more effort is needed to improve our conservation efforts.

\section{Acknowledgements}

We are grateful to D. Kramer for contributions and suggestions at every stage. We thank A. Griffin, K. Abbott, J. Curtis, C. Hall, P. Leighton, J. Morand-Ferron, E. Dolgin, I. Morgan and N. Sager for comments on earlier drafts of this review. We would also like to thank two anonymous reviewers for their comments. Research was supported by the Natural Sciences and Engineering Research Council of Canada.

\section{References}

Aengus, W.L., Millam, J.R. (1999). Taming parent-reared orange-winged Amazon parrots by neonatal handling. Zoo Biol. 18, 177-187.

Allendorf, F.W. (1993). Delay of adaptation to captive breeding by equalizing family size. Conserv. Biol. 7 , 416-419.

Anthony, L.L., Blumstein, D.T. (2000). Integrating behavior into wildlife conservation: the multiple ways that behavior can reduce. Biol. Conserv. 95, 303-315.

Arcese, P. (2003). Individual quality, environment, and conservation. In Animal behaviour and wildlife conservation: 271-296. Festa-Bianchet, M. \& Apollonio, M. (Eds). Washington: Island Press.

Archer, J. (1973). Tests for emotionality in rats and mice: a review. Anim. Behav. 21, 205-235.

Armitage, K.B. (1986). Individuality, social behavior, and reproductive success in yellow-bellied marmots. Ecology 67, 1186-1193.

Arnold, S.J. (1995). Monitoring quantitative genetic variation and evolution in captive populations. In Population management for survival and recovery: analytical methods and strategies in small population conservation: 295-317. Ballon, J.D., Gilpin, M. \& Foosc, T.J. (Eds). New York: Columbia University Press.

Ashley, M.V., Willson, M.F., Pergams, O.R.W., O’Dowd, D.J., Gende, S.M. \& Brown, J.S. (2003). Evolutionary enlightened management. Biol. Conserv. 111, 115-123.

Banks, P.B., Norrdahl, K. \& Korpimäki, E. (2003). Mobility decision and the predation risks of reintroduction. Biol. Conserv. 103, 133-138.

Belyaev, D.K. (1979). Destabilizing selection as a factor in domestication. J. Hered. 70, 301-308.
Berger, J., Swenson, J.E. \& Persson, I.L. (2001). Recolonizing carnivores and naive prey: conservation lessons from Pleistocene extinctions. Science 291, 1036-1039.

Boissy, A. (1995). Fear and fearfulness in animals. $Q$. Rev. Biol. 70, 165-191.

Box, H.O. (1991). Training for life after release: simian primates as examples. Symp. Zool. Soc. Lond. 62, 111-123.

Buss, A.H., Chess, S., Goldsmith, H.H., Hinde, R.A., McCall, R.B., Plomin, R., Rothbart, M.K. \& Thomas, A. (1987). What is temperament: four approaches. Child Dev. 58, 505-529.

Carlstead, K. (1996). Effects of captivity on the behavior of wild mammals. In Wild mammals in captivity: principles and techniques: 317-333. Kleiman, D.G., Allen, M.E., Thompson, K.V. \& Lumpkin, C.S. (Eds). Chicago: The University of Chicago Press.

Carlstead, K. (1999) Constructing behavior profiles of zoo animals: incorporating behavioral information into captive population management. Behavior and Husbandry Advisory Group, AZA.

Carlstead, K., Fraser, J., Bennett, C. \& Kleiman, D.G. (1999a). Black rhinoceros (Diceros bicornis) in US zoos: II. behavior, breeding success, and mortality in relation to housing facilities. Zoo Biol. 18, 35-52.

Carlstead, K., Mellen, J. \& Kleiman, D.G. (1999b). Black rhinoceros (Diceros bicornis) in US zoos: I. Individual behavior profiles and their relationship to breeding success. Zoo Biol. 18, 17-34.

Clark, A.B. \& Ehlinger, T.J. (1987). Pattern and adaptation in individual behavioral differences. In Perspectives in ethology: 1-47. Bateson, P.P.G. \& Klopfer, P.H. (Eds). New York: Plenum Press.

Clemmons, J.R. \& Buccholz, R. (1997). Behavioral approaches to conservation in the wild. New York: Cambridge University Press.

Cleveland, A., Westergaard, G.C., Trenkle, M.K. \& Higley, J.D. (2004). Physiological predictors of reproductive outcome and mother-infant behaviors in captive rhesus macaque females (Macaca mulatta). Neuropsychopharmacology 29, 901-910.

Coleman, K. \& Wilson, D.S. (1998). Shyness and boldness in pumpkinseed sunfish: individual differences are contextspecific. Anim. Behav. 56, 927-936.

Coltman, D.W., O'Donoghue, P., Jorgenson, J.T., Hogg, J.T., Strobeck, C. \& Festa-Bianchet, M. (2003). Undesirable evolutionary consequences of trophy hunting. Nature 428, 655-658.

Conover, D.O. \& Munch, S.B. (2002). Sustaining fisheries yields over evolutionary time scales. Science 297, 94-96.

Coss, R.G. \& Biardi, J.E. (1997). Individual variation in the anti-snake behavior of California ground squirrels (Spermophilus beecheyi). J. Mammal. 78, 294-310.

Crockett, C.M., Shimoji, M. \& Bowden, D.M. (2000). Behavior, appetite, and urinary cortisol responses by adult female pigtailed macaques to cage size, cage level, room change, and ketamine sedation. Am. J. Primatol. 52, 63-80. 
Curio, E. (1996). Conservation needs ethology. Trends Ecol. Evol. 11, 260-263.

Darwin, C. (1882). The variation of animals and plants under domestication. London: Murray.

De Boer, S.F., van der Vegt, B.J. \& Koolhaas, J.M. (2003). Individual variation in aggression in feral rodent strains: a standard for the genetics of aggression and violence? Behav. Genet. 33, 485-501.

DeFries, J.C., Gervais, M.C. \& Thomas, E.A. (1978). Response to 30 generations of selection for open-field activity in laboratory mice. Behav. Genet. 8, 3-21.

Dingemanse, N.J. (2003) Natural selection and avian personality in a fluctuating environment. Thesis, Utrecht University, ISBN 90-6464877-8.

Dingemanse, N.J., Both, C., Drent, P. \& Tinbergen, J.M. (2004). Fitness consequences of avian personalities in a fluctuating environment. Proc. R. Soc. Lond. 271, 847-852.

Dingemanse, N.J., Both, C., Drent, P., van Oers, K. \& van Noordwijk, A.J. (2002). Repeatability and heritability of exploratory behavior in great tits from the wild. Anim. Behav. 64, 929-938.

Dingemanse, N.J., Both, C., van Noordwijk, A.J., Ruttenm, A.L. \& Drent, P.J. (2003). Natal dispersal and personalities in great tits (Parus major). Proc. R. Soc. Lond. 270, 741-747.

Drent, P., van Oers, K. \& van Noordwijk, A.J. (2003). Realised heritability of personalities in the great tit (Parus major). Proc. R. Soc. Lond. 270, 45-51.

Earley, R.L., Hsu, Y.\& Wolf, L.L. (2000). The use of standard aggression testing methods to predict combat behavior and contest outcome in Rivulus marmoratus dyads (Teleostei: Cyprinodontidae). Ethology 106, 743-761.

Endler, J.A. (1986). Natural selection in the wild. Princeton, NJ: Princeton University Press.

Fairbanks, L.A. (1996). Individual differences in maternal style. Causes and consequences for mothers and offspring. Adv. Stud. Behav. 25, 579-611.

Falconer, D.S. \& Mackay, T.F.C. (1996). Introduction to quantitative genetics. 4th edn. New York: Longman.

Faure, J.-M. \& Mills, A. (1998). Improving the adaptability of animals by selection. In Genetics and the behavior of domestic animals. Grandin, T. (Ed.). San Diego, CA: Academic Press.

Festa-Bianchet, M. (2003). Exploitative wildlife management as a selective pressure for the life history evolution of large mammals. In Animal behaviour and wildlife conservation: 191-207. Festa-Bianchet, M. \& Apollonio, M. (Eds). Washington: Island Press.

Festa-Bianchet, M. \& Apollonio, M. (2003). Animal behaviour and wildlife conservation. Washington: Island Press.

Frankham, R., Hemmer, H., Ryder, O.A., Cothran, E.G., Soulé, M.E., Murray, N.D. \& Snyder, M. (1986). Selection in captive populations. Zoo Biol. 5, 127-138.

Frankham, R., Manning, H., Margan, S.H. \& Briscoe, D.A. (2000). Does equalization of family sizes reduce genetic adaptation to captivity? Anim. Conserv. 4, 357-363.
Fraser, D.F., Gilliam, J.F., Daley, M.J., Le, A.N. \& Skalski, G.T. (2001). Explaining leptokurtic movement distributions: intrapopulation variation in boldness and exploration. Am. Nat. 158, 124-135.

Fromont, E., Courchamp, F., Artois, M. \& Pontier, D. (1997). Infection strategies of retroviruses and social grouping of domestic cats. Can. J. Zool. 75, 1994-2002.

Gerken, M. \& Petersen, J. (1992). Heritabilities for behavioral and production traits in Japanese quail (Coturnix coturnix japonica) bi-directionally selected for dust bathing activity. Poult. Sci. 71, 779-788.

Gilligan, D.M. \& Frankham, R. (2003). Dynamics of genetic adaptation to captivity. Conserv. Genet. 4, 189-197.

Godin, J.G.J. \& Davis, S.A. (1995). Who dares, benefits predator approach behavior in the guppy (Poecilia reticulata) deters predator pursuit. Proc. R. Soc. Lond. 259, 193-200.

Godin, J.G.J. \& Dugatkin, L.A. (1996). Female mating preference for bold males in the guppy, Poecilia reticulata. Proc. Natl. Acad. Sci. USA 93, 10262-10267.

Gosling, L.M. \& Sutherland, W.J. (2000). Behavior and conservation. New York: Cambridge University Press.

Gosling, S.D. (2001). From mice to men: what can we learn about personality from animal research? Psychol. Bull. 127, 45-86.

Grandin, T. (1998). Genetics and the behavior of domestic animals. San Diego, CA: Academic Press.

Greenberg, R. \& Mettke-Hoffman, C. (2001). Ecological aspects of neophobia and neophilia in birds. Curr. Ornithol. 16, 119-178.

Griffin, A.S., Blumstein, D.T. \& Evans, C.S. (2000). Training captive-bred or translocated animals to avoid predators. Conserv. Biol. 14, 1317-1326.

Griffith, B., Scott, J.M., Carpenter, J.W. \& Reed, C. (1989). Translocation as a species conservation tool - status and strategy. Science 245, 477-480.

Hansen, S.W. (1996). Selection for behavioral traits in farm mink. Appl. Anim. Behav. Sci. 49, 137-148.

Hansen, S.W. \& Møller, S.H. (2001). The application of a temperament test to on-farm selection of mink. Acta Agric. Scand. Suppl. 30, 93-98.

van Heezik, Y. \& Seddon, P.J. (2001). Influence of group size and neonatal handling on growth rates, survival, and tameness of juvenile houbara bustards. Zoo Biol. 20, 423-433.

Hendry, A.P. \& Kinnison, M.T. (1999). The pace of modern life: measuring rates of contemporary microevolution. Evolution 53, 1637-1653.

Kleiman, D.G. (1989). Reintroduction of captive mammals for conservation. Bioscience 39, 152-161.

Koolhaas, J.M., Korte, S.M., De Boer, S.F., van der Vegt, B.J., van Reenen, C.G., Hopster, H., De Jong, I.C., Ruis, M.A.W. \& Blokhuis, H.J. (1999). Coping styles in animals: current status in behaviour and stress-physiology. Neurosci. Biobehav. Rev. 23, 925-935. 
Korhonen, H., Hansen, S.W., Malmkvist, J. \& Houbak, B. (2000). Effect of capture, immobilization and handling on rectal temperatures of confident and fearful male mink. J. Anim. Breed. Genet. 117, 337-345.

Korhonen, H., Jauhiainen, L. \& Rekilä, T. (2002). Effect of temperament and behavioural reactions to the presence of human during the pre-mating period on reproductive performance in farmed mink (Mustela vison). Can. J. Anim. Sci. 82, 275-282.

Korhonen, H. \& Niemela, P. (1995). Temperament and reproductive success in farm bred silver foxes housed with and without platforms. J. Anim. Breed. Genet. 113, 209-218.

Künzl, C., Kaiser, S., Meier, E. \& Sachser, N. (2003). Is a wild mammal kept and reared in captivity still a wild animal? Horm. Behav. 43, 187-196.

Lacy, K.E. \& Martins, E.P. (2003). The effect of anthropogenic habitat usage on the social behavior of vulnerable species, Cyclura nubila. Anim. Conserv. 6, 3-9.

Loebel, D.A., Nurthen, R.K., Frankham, R., Briscoe, D.A. \& Craven, D. (1992). Modeling problems in conservation genetic using captive Drosophila populations: consequence of equalizing founder representation. Zoo Biol. 11, 319-332.

Lord, A., Waas, J.R. \& Innes, J. (1997). Effects of human activity on the behavior of northern New Zealand dotterel Charadrius obscurus aquilonius chicks. Biol. Conserv. 82, 15-20.

Louis, S. \& Le Beere, M. (2000). Adjustment in flight distance from humans by Marmota marmota. Can. J. Zool. 78, 556-563.

Lynch, M. \& Walsh, B. (1998). Genetics and analysis of quantitative traits. Sunderland, MA: Sinauer Associates.

Maestripieri, D. (1993). Maternal anxiety in rhesus macaques (Macaca mulata) II. Emotional bases of individual differences in mothering style. Ethology 95, 32-42.

Malmkvist, J., Houbak, B. \& Hansen, S.W. (1997). Mating time and litter size in farm mink selected for confident or timid behavior. Anim. Sci. 65, 521-525.

Malmkvist, J.B. \& Hansen, S.W. (2002). Generalization of fear in farm mink, Mustela vison, genetically selected for behavior towards humans. Anim. Behav. 64, 487-501.

Manteca, X. \& Deag, J.M. (1993). Individual differences in temperament of domestic animals: a review of methodology. Anim. Welf. 2, 247-268.

Marliave, J.B., Gergits, W.F. \& Aota, S. (1993). F10 Pandalid shrimp - sex determination, DNA and dopamine as indicators of domestication and out crossing for wild pigment pattern. Zoo Biol. 12, 435-451.

Mattson, D.J., Blanchard, B.M. \& Knight, R.R. (1992). Yellowstone grizzly bear mortality, human habituation, and whitebark-pine seed crops. J. Wildl. Mgmt 56, 432-442.

McPhee, M.E. (2004). Generations in captivity increases behavioral variance: considerations for captive breeding and reintroduction programs. Biol. Conserv. 115, 71-77. van Oers, K., Drent, P.J. \& van Noordwijk, A.J. (2004). Realized heritability and repeatability of risk-taking behavior in relation to avian personalities. Proc. R. Soc. Lond. 271, 65-73.

Olson, T.L., Gilbert, B.K. \& Squibb, R.C. (1997). The effects of increasing human activity on brown bear use of an Alaskan river. Biol. Conserv. 82, 95-99.

Pontier, D., Fromont, E., Courchamp, F., Artois, M. \& Yoccoz, N.G. (1998). Retroviruses and sexual size dimorphism in domestic cats (Felis catus L.). Proc. R. Soc. Lond. 265, 167-173.

Price, E.O. (2002). Animal domestication and behavior. London, UK: CAB International.

Réale, D. \& Festa-Bianchet, M. (2003). Predator-induced natural selection on temperament in bighorn ewes. Anim. Behav. 65, 463-470.

Réale, D., Galland, B.Y., Leblanc, M. \& Festa-Bianchet, M. (2000). Consistency of temperament in bighorn ewes and correlates with behaviour and life history. Anim. Behav. 60, 589-597.

Sih, A., Bell, A. \& Johnson, J.C. (2004). Behavioral syndromes: an ecological and evolutionary overview. Trends Ecol. Evol. 19, 372-378.

Sih, A., Kats, L.B. \& Maurer, E.F. (2000). Does phylogenetic inertia explain the evolution of ineffective antipredator behavior in a sunfish-salamander system? Behav. Ecol. Sociobiol. 49, 48-56.

Stamps, J.A. (1991). Why evolutionary issues are reviving interest in proximate behavioral mechanism. Am. Zool. 31, 333-348.

Steel, B.M. \& Hogg, J.T. (2003). Measuring individual quality in conservation and behavior. In Animal behaviour and wildlife conservation: 243-270. FestaBianchet, M. \& Apollonio, M. (Eds). Washington: Island Press.

Stockwell, C.A., Hendry, A.P. \& Kinnison, M.T. (2003). Contemporary evolution meets conservation biology. Trends Ecol. Evol. 18, 94-101.

Sutherland, W.J. (1998). The importance of behavioral studies in conservation biology. Anim. Behav. 56, 801-809.

Thomas, C.D., Baguette, M. \& Lewis, O.T. (2000). Butterfly movement and conservation in patchy landscapes. In Behavior and conservation: 85-104. Gosling, L.M. \& Sutherland, W.J. (Eds). Cambridge: Cambridge University Press.

Travis, J.M.J. \& Dytham, C. (1999). Habitat persistence, habitat availability and the evolution of dispersal. Proc. $R$. Soc. Lond. 266, 723-728.

Trefilov, A., Berard, J., Krawczak, M. \& Schmidtke, J. (2000). Natal dispersal in rhesus macaques is related to serotonin transporter gene promoter variation. Behav. Genet. 30, 295-301.

Trut, L.N. (1999). Early canid domestication: the farm fox experiment. Am. Sci. 87, 160-169. 
Walsh, R.N. \& Cummins, R.A. (1976). The open-field test: a critical review. Psychol. Bull. 83, 482-504.

Wielebnowski, N.C. (1999). Behavioral differences as predictors of breeding status in captive cheetahs. Zoo Biol. 18, 335-349.

Wilson, D.S., Clark, A.B., Coleman, K. \& Dearstyne, T. (1994). Shyness and boldness in humans and other animals. Trends Ecol. Evol. 9, 442-445.

Wolf, C.M., Griffith, B., Reed, C. \& Temple, S.A. (1998). Avian and mammalian translocations: update and reanalysis of 1987 survey data. Conserv. Biol. 10, 1142-1154.
Woodroffe, R. (2003). Dispersal and conservation: a behavioral perspective on metapopulation persistence. In Animal behaviour and wildlife conservation: 33-48. Festa-Bianchet, M. \& Apollonio, M. (Eds). Washington: Island Press.

Woodworth, L.M., Montgomery, M.E., Briscoe, D.A. \& Frankham, R. (2002). Rapid genetic deterioration in captive populations: causes and conservation implications. Conserv. Genet. 3, 277-288.

Zhang, G., Swaisgood, R.R. \& Zhang, H. (2004). Evaluation of behavioral factors influencing reproductive success and failure in captive giant pandas. Zoo Biol. 23, 15-31. 